\title{
On the optimal realignment of a contest: The case of college football
}

\begin{abstract}
This paper examines the relationship between demand and scheduling in college football. We first derive two different metrics for team quality, and then use those metrics to see how they impact attendance. We find that there is a positive interaction between the quality of the teams. Then various simulations are run to see how attendance would change under different scheduling scenarios. If teams are put into conferences based on the team quality measures, the average per game attendance only rises $1 \%$ to $2 \%$. This is true if one year or ten year quality measures are used. However, our simulation suggests that this effect would be more than offset, mainly because schools with larger capacity would play fewer home games and so aggregate attendance would fall. We discuss whether this effect would be mitigated by capacity adjustments in the longer term.
\end{abstract}

\section{The Question}

The production of team sports involves a form of matching. In most professional leagues the membership is fixed and there is no choice in the selection of matches (the most common format of a league is a round robin where every team plays every other team twice, once at home and once away). College football is rather different. Teams belong to conferences and are usually required to schedule a certain number of games against conference rivals, but they are also free to schedule additional games against opposition of their choice. Moreover, the membership of conferences has always been fluid, and is going through a period of rapid change at the moment. According to Wikipedia 93 schools have jumped to a new conference (full membership) since 2010. ${ }^{1}$

The aim of this paper is to develop a model for optimally matching college football teams in competition. Our notion of optimal matching is very simple, not unlike Becker's (1973) theory of marriage. Each team has a productivity (team quality), $Z_{i}$, which they bring to any match. The productivity of a match is the sum of individual productivities plus the interaction of the two: $\pm_{i} Z_{i}+{ }^{2} Z_{j}+{ }_{i}^{3} Z_{i} Z_{i}$. This productivity then determines demand: the number of people who are willing to pay to watch the game.

One interpretation of the interaction term is that it represents the demand for competitive balance $\left({ }_{i}^{3}>0\right)$, which has long been considered by economists to be an important determinant of the demand for team sports (see e.g. Borland and McDonald (2003)). This element alone suggests that positive assortative matching is optimal - attendance is maximized globally when teams of similar quality play against each other. However, even if this is not true, positive assortative matching may still be optimal for individual teams $\left({ }^{2}>0\right.$

This is the author manuscript accepted for publication and has undergone full peer review but has not been through the copyediting, typesetting, pagination and proofreading process, which may lead to differences between this version and the Version of Record. Please cite this article as doi: $10.1111 /$ ecin.12493

This article is protected by copyright. All rights reserved. 
and ${ }^{3}{ }_{i}=0$ ). Under this assumption, if the home team retains all the gate money it will be revenue maximizing to play the best opponents.

There are two potential confounding factors in this analysis. First, there is the phenomenon of "rivalry games" - match-ups between teams that are deemed to be of historical significance in their own right, e,g, Michigan/Ohio State, Alabama/Auburn, etc. Typically these rivals are also geographically close. Often these rivals are well matched, but it may be that even when they are not well matched demand remains high. The second confounding factor relates to stadium capacity. Designing an attendance maximizing schedule will typically mean scheduling more games in the stadiums with the largest capacity. If these stadiums are homes of the strongest teams, then more positive assortative matching can actually reduce attendance: if two strong teams with large stadiums play each other, by implication one large stadium goes empty that day. ${ }^{2}$ In our analysis we find that rivalry games have a statistically significant positive effect on demand, but that this does not have a large effect on aggregate attendance. However, we do find that capacity effects are larger.

In this paper we use the terms "optimal" and "attendance maximizing" interchangeably. Of course, it can be argued that what is optimal for a team involves more than attendance considerations. Strong teams scheduling games against weak teams might thereby improve their end of the season ranking. The impact on demand is not clear, since fans might not want to go to watch such games, but winning these games might increase demand later in the season due to their higher winning percentage.

We develop a simple empirical model to analyze these issues. Based on a sample of college football games we estimate attendance as a function of various observables including the quality of the teams. We then identify the attendance maximizing conference structure, which matches teams of roughly equal quality across the season, and calculate the expected attendance conditional on this structure. Our results show that the attendance maximizing scheduling would increase per game attendance by an average of $1.5 \%$. We conjecture that TV audiences are more sensitive to quality, so that the revenue benefits through TV would be even greater. ${ }^{3}$ However, this increase in demand is not enough to offset the stadium capacity effect identified above. In our balanced schedule the fact that all teams must then play half of their games on the road will imply that some larger stadiums will go empty and therefore total attendance would be smaller. We argue that this result is a consequence of current capacity constraints which are a product of the existing scheduling arrangements, and that in the longer term capacity would adjust to a revised scheduling scheme and so mitigate this effect. 
The next section gives some background on the economics of scheduling in college football. Section 3 describes our data and methodology, then we consider the results of the estimation in Section 4. Section 5 describes the simulated conference structure, and section 6 concludes.

\section{Background}

\subsection{Matching Model}

College football resembles a marriage market in the sense that each game played requires that both sides agree to play, and both have many alternatives from whom to choose. Surprisingly little has been written in the academic literature on this problem. In most team sports this problem is trivial because competition is organized on a league basis and opponents are dictated by the system adopted. For instance, the NFL has formula which requires each team to play two games against each of their divisional rivals, divisional rivals have fourteen out of sixteen games against common opponents, while the remaining two are decided by the standings of the previous season. College football, while also being built around league play, gives far more latitude to teams to decide who they play. For example, in the Big 10 teams currently have to play 8 conference games in the season, five against members of their own division, two against teams from the other division (on a rotating basis) and one that it plays every year. However, teams play a 12 game season and are at liberty to play any four teams that will agree to play with them. Teams are also allowed to schedule a majority of their games at their home stadium, provided other teams agree to play there. Moreover, while most popular sports leagues are stable over time, college football is subject to realignment, markedly so in recent years. Colleges are seeking out the best collection of competitors that they can find.

Matching theory suggests there should be few problems in finding optimal matches. Even in the absence of a pricing mechanism there are well known theorems, e.g. Gale and Shapley (1962), which suggest that optimal matches are feasible. Their model of a marriage market works via the "deferred acceptance mechanism" - one gender makes offers to as many partners as they wish and the other rejects all offers but one which is held, and then a second round of offers is made conditional on (deferred) acceptances received, and the process repeats until no new offers are received. This mechanism has the nice property that at equilibrium no one fails to make a match with someone that (a) they would prefer and (b) would also prefer switch their match. This is consistent with positive assortative matching, where each agent has a type, and matches are made between similar types. Becker (1973) shows that positive assortative mating is an equilibrium in a marriage market which ensures that aggregate output from matches is maximized. The idea of positive assortative matching has been applied to explaining the distribution of wages (Sattinger 1993) and economic 
development (Kremer 1993). In general, frictions may exist which prevent efficient assortative matching, while incomplete information and moral hazard my lead to inefficient matching (see e.g. Legros and Newman (2002)). For example, Fréchette et al. (2007) show that when college football bowl games were scheduled later in the season with more information about the quality of the teams, it is possible to match teams more evenly and efficiencies were gained as evidenced by higher television ratings.

One difficulty in identifying optimal matches for college football teams is that the objectives of each college are not clear. We will assume that an optimal schedule is one that maximizes total output which we will measure by total attendance. This will also imply that the schedule maximizes the total attendance of each team, subject to playing a schedule of $5,6,7$, or 8 home games. However, decision makers within the college may have different objectives. Coaches will want a schedule which maximizes the probability of reaching the best possible Bowl game, Athletic Directors may want to maximize the resources provided the department, which might depend on meeting the demands of particular constituencies (e.g. the preferences of boosters) and University Presidents may have strategic goals which go beyond sport and relate to student recruitment, college profile and donors. This list of decision makers is not necessarily exhaustive.

However, we do not believe that these objectives are widely at variance with output maximization as we have defined it. First, the rating schemes which determine the allocation of teams to Bowl games tend to favor those teams that play stronger schedules, all else equal, and so deliberately choosing a weak schedule can be counter-productive (Keener (1993)). Second, there are studies which have shown that successful athletic programs, especially in the revenue sports, tend to align with broader academic goals such as recruitment and donations. $^{4}$

\subsection{Matching and the uncertainty of outcome hypothesis}

With the exception of Fréchette (2007), the sports literature has not focused on the matching issue for the reasons given above. However, it has focused on a related concept - the uncertainty of outcome hypothesis (the original article in this literature is Rottenberg (1956)). In our terms, this asserts that a match will be more attractive (larger attendance) if the strength of the two sides is closely matched than if they are unevenly matched. This question has generated a large literature which has been surprisingly inconclusive. Thus a survey by McDonald and Borland (2003) found:

"Of 18 studies identified, only about three provide strong evidence of an effect on attendance. Other studies provide mixed evidence that suggests a negative effect on attendance of increasing home win probability only when that win probability is above about two thirds. 
The majority of studies find either that there is no significant relation between difference in team performance and attendance, or more directly contradictory, that attendance is monotonically increasing in the probability of a home-team win."

We have reviewed 15 studies published since then and the results are shown in Table 1. There is some variability in the focus of these studies, but generally they test for the effect on demand of the quality of the home team, the quality of the away team, and the expected difference in performance of the two teams. Quality is typically measured either by the recent winning records of the teams or by the pre-match betting odds on the teams. Almost all of the studies find that demand is increasing in the quality of the home team. When tested for, it is generally found that demand is also increasing in the quality of the away team (in the words of Coates and Humphreys (2010) "fans want to see good teams play"). The results for the competitive balance measures are generally more ambiguous, in the line with the earlier research. Several studies suggest that the optimal winning percentage/probability of winning for the home team is in the region of $66 \%$. Seen from our perspective the ambiguity is perhaps not surprising. If demand is increasing in qualities of the teams taken separately and in their interaction as well, then picking up the latter effect is likely to be difficult econometrically.

Measures of differences in team quality, whether based on win/loss records or betting odds fail to generate a consistent pattern, are sometimes perversely signed, and often entail quadratic terms with impossible implications. For example, a finding that demand is decreasing in both the absolute difference in win loss records and its square would normally be taken as confirmation of the uncertainty of outcome hypothesis. However, the implication of this is that a very weak home team playing against a very strong home team could face negative demand.

In our model, based on our discussion of assortative matching and Becker's marriage model, we view the value of the match as dependent on both the qualities of the home and away teams taken separately and the product of the two qualities. Thus at worst a highly unbalanced match could contribute nothing to demand other than the quality of the strong team.

\section{Data and Methodology}

\subsection{Team Quality Measures}

Our first step is to measure team quality. Football Bowl Subdivision games were used to create team quality variables. Our sample consists of 14,924 games played between 1990 and 
2010. However, since lagged variables were used, the games from 1990 were not used so the estimation had 14,278 observations.

We identify quality in two different ways: Method 1: We estimate the expected margin of victory for each game based on a weighted average of past performance measured by win percentage and the strength of schedule for each team. A team's strength of schedule is the average winning percentage of a team's opponents up to the date of the game. Therefore, this non-linear estimation takes into account where the game is played (home, away, or neutral), the winning percentage of each team for the current and previous year, and the strength of schedule for each team for the current and previous year. The weighting between the current and previous year depends on how many games the teams have played in the current season.

The equation is given by,

$$
\begin{aligned}
& M O V=\beta_{1}+\beta_{2} \text { Neutral }+\beta_{3}\left(1-\frac{1}{N_{H}^{\beta_{1} 1}}\right) \text { win } \%_{h, t, N_{H}}+\beta_{4}\left(\frac{1}{N_{H}^{\beta_{1} 1}}\right) \text { win } \%_{h, t-1, \bar{N}}+ \\
& \beta_{5}\left(1-\frac{1}{N_{H}^{\beta_{1} 1}}\right) \operatorname{SOS}_{h, t, N_{H}}+\beta_{6}\left(\frac{1}{N_{H}^{\beta_{1} 1}}\right) \operatorname{SOS} S_{h, t-1, \bar{N}}+\beta_{7}\left(1-\frac{1}{N_{A}^{\beta_{11}}}\right) w i n \%_{a, t, N_{A}}+ \\
& \beta_{8}\left(\frac{1}{N_{A}^{\beta_{11}}}\right) \operatorname{win}_{a, t-1, \bar{N}}+\beta_{9}\left(1-\frac{1}{N_{A}^{\beta_{11}}}\right) \operatorname{SOS}_{a, t, N_{A}}+\beta_{10}\left(\frac{1}{N_{A}^{\beta_{11}}}\right) \operatorname{SOS}_{a, t-1, \bar{N}}
\end{aligned}
$$

where $M O V$ is the margin of victory for the home team, Neutral is equal to one if the game is on a neutral field, $N_{H}$ is the $n^{\text {th }}$ game of the season for the home team, $N_{A}$ is the $n^{\text {th }}$ game of the away team, win $\%$ is the winning percentage, SOS is the strength of schedule ${ }^{5}, h$ represents the home team, $a$ represents the away team, $t$ is the season, and $\bar{N}$ denotes that the winning percentage or strength of schedule is calculated at the end of the previous season. Table 2 gives the parameter estimates and t-statistics, the model correctly predicts $73 \%$ of games.

This model was then used to create a quality metric for every team for each game. A team's quality value was computed using the parameter estimates from equation (1) in addition to their winning percentages for this year and the previous year, as well as the strength of schedule for both years. Home team parameter estimates were used, but since there is no road team identified a value of .5 was used for the visiting team's winning percentage and strength of schedule. So, this measure represents the expected margin of victory against a .500 team, so that the metric for team $i$ during season $t$ for the $N_{i}^{t h}$ game is given by, 


$$
\begin{aligned}
& \operatorname{MOV}_{i, t, N_{H}}^{*}=\beta_{1}+\beta_{2}+\beta_{3}\left(1-\frac{1}{N_{H}^{\beta_{11}}}\right) \operatorname{win}_{\%_{i, t, N_{H}}}+\beta_{4}\left(\frac{1}{N_{H}^{\beta_{11}}}\right) \operatorname{win} \%_{i, t-1, \bar{N}}+ \\
& \beta_{5}\left(1-\frac{1}{N_{H}^{\beta_{11}}}\right) \operatorname{SOS}_{i, t, N_{H}}+\beta_{6}\left(\frac{1}{N_{H}^{\beta_{1}}}\right) \operatorname{SOS}_{i, t-1, \bar{N}}+\beta_{7}\left(1-\frac{1}{N_{H}^{\beta_{11}}}\right) \cdot 5+ \\
& \beta_{8}\left(\frac{1}{N_{H}^{\beta_{1}}}\right) \cdot 5+\beta_{9}\left(1-\frac{1}{N_{H}^{\beta_{1}}}\right) \cdot 5+\beta_{10}\left(\frac{1}{N_{H}^{\beta_{1}}}\right) \cdot 5
\end{aligned}
$$

$M O V_{i, t, N_{H}}^{*}$ was then used as a quality metric for the home team, $M O V_{H}$, and the away team, $M O V_{A}$. A constant was then added to ensure that $M O V_{H}>0$ and $M O V_{A}>0$.

Method 2: We also construct an ELO rating for each team. ${ }^{6} E L O$ ratings are widely used in competitions where the organizers want to match competitors of similar ability, most notably in chess. An ELO rating is built up by playing games, where the result of each game generates an addition or subtraction depending on win or loss, where the size of the adjustment is calibrated according to the pre-match expectation of the outcome, which is based on the $E L O$ ratings going into the game. For each competitor the initial value is arbitrary, but once enough games have been played ELO ratings provide a consistent measure of relative performance. Thus for each game the expectation of a win for team $i$ against team $j$ is

$$
E_{i j}=\frac{1}{1+10^{\left(E L O_{i}-E L O_{j}\right) / 400}}
$$

And the rating is updated according to

$$
E L O_{i}^{\prime}=E L O_{i}+K\left(R_{i j}-E_{i j}\right)
$$

Where $R$ is the result (win $=1$, loss $=0$ ) and $K$ is a scaling factor. There is some controversy over the appropriate value of the scaling factor, but we chose the commonly used value of 50 . However, we do not believe this significantly affects the estimation of our demand model. To construct the $E L O$ ratings we used results dating back 20 years so that even our earliest demand observations are based on around ten years of results.

\subsection{Attendance Estimation}

We collected attendance data from various sources for 4839 college football games played between 2001 and 2010. However, we do not have attendance for all Football Bowl Subdivision games over this time period. Attendance data is more readily available for recent games. For example, we have 245 observations in 2001 , but 729 in $2010 .^{7}$ 
We now use our alternative measures of quality to estimate demand. Our hypothesis is that attendance is a function of both home and away team quality. As well as team quality we assume that demand is a function of year and stadium fixed effects and monthly dummies. We also allow for the effect of "rivalry" games. Clearly the definition of a rivalry game is somewhat arbitrary, but we want to capture the possibility that certain games may add to demand even if the quality of the teams is poor. We suspect that Michigan v Ohio State would sell out no matter who played for the teams. To capture rivalry effects we invited six colleagues to choose from a list of all match-ups from the last 20 years (2769) and indicate which match-ups they thought were true "rivalry" games. Only about $15 \%$ of these games have been played more than 15 times, whereas one might expect true rivalry games would be played almost every year. We decided to designate match-ups as rivalry games if two thirds or more (at least 4 of 6 ) of our assessors thought that they were. This generated a total of 31 rivalry games, which are listed in Table 3 . Table 4 has summary statistics of the data used to estimate attendance.

Although we do not have data on prices, these are likely to be captured by the combination of stadium fixed effect and year dummies. A number of stadiums sell out on a regular basis and so we use Tobit as well as OLS to estimate demand. Ideally we would like to know the exact stadium capacity at each game, since this can vary significantly for a number of reasons. There are differences in how teams report attendance and stadium capacity can vary for each team from year to year or even game to game.

We estimate the following demand model

$$
y_{i}^{*}=\beta_{0}+X_{i}^{H} \beta_{1}+X_{i}^{A} \beta_{2}+X_{i}^{H A} \beta_{3}+X_{i}^{\text {month }} \beta_{4: 8}+X_{i}^{\text {rival }} \beta_{9}+X_{i}^{y r} \beta_{10: 20}+X_{i}^{\text {stad }} \beta_{21: 145}+\epsilon_{i}
$$

where $y_{i}^{*}$ is the attendance data and we observe $y_{i}=y_{i}^{*}$ only if the attendance is not censored. In order for a game to be denoted as censored (sold-out), it met three criteria. First, the attendance had to be least $98 \%$ of the maximum attendance value for that stadium. Second, there had to be at least two games that were $98 \%$ or more of the maximum attendance value for the stadium. Third, at least one-tenth of the games in the stadium in the sample had to be at least $98 \%$ of the maximum value of the stadium. ${ }^{8}$ Therefore, the threshold for a sell-out varied by team. Teams with larger stadiums needed a higher attendance to be considered a sell-out when compared with teams with smaller stadiums. These criteria resulted in $16.3 \%$ of games being denoted as a sell-out, after Notre Dame was thrown out of the sample since all of their games qualified as a sell-out.

$X_{i}^{H}$ represents the strength of the home team (either $M O V$ or $E L O$ ), $X_{i}^{A}$ is strength of the away team, $X_{i}^{H A}$ is the interaction of the strength of the home and away teams, $X_{i}^{\text {month }}$ 
represents month dummy variables, $X_{i}^{r v a l}$ is a dummy variable for rivalry games, $X_{i}^{y r}$ represents year dummy variables, $X_{i}^{\text {stad }}$ represents stadium dummy variables, and $\tilde{o}_{i}$ is the error term.

\section{Results}

The demand estimation results are presented in Table 5. Using both measures ( $M O V$ and $E L O$ ), we ran an OLS on the full sample, and OLS using only teams without censored observations $^{9}$, a Censored Least Absolute Deviation (CLAD) model as described in Powell (1984), and a Tobit model. Both our MOV and our ELO measures of quality show that the strength of the home team and the strength of the away team add significantly to demand, as one might expect. The interaction of the home and away quality measures, which can be interpreted as the effect of competitive balance on demand, is insignificant in the full sample OLS and CLAD estimations but significant and with the expected sign in the sub-sample OLS and Tobit estimations. One interpretation of this is that the teams with capacity constraints are generally the stronger teams who have big rivals but also have a habit of scheduling very weak teams from time to time. If capacity constraints are not allowed for, then it might appear that playing minnows does not reduce demand, but once capacity constraints are included the effect of the competitive imbalance becomes apparent. Our rivalry measure is also strongly significant and adds significantly to demand.

\section{Schedule Simulations}

\subsection{Random Schedule}

Based on this analysis we are able to construct simulated schedules for the 2010 season and estimated the demand that would be associated with these alternative schedules. First, we compared the actual schedule to a random schedule. 100 simulations were run where each week the visiting teams were randomly assigned one of the home teams, and so the number of home games and total number of games did not change for teams. The results in Table 10 are the averages from the 100 simulations, and we discuss these below.

\subsection{Stratified Schedules}

Next, we simulated a stratified schedule based on the quality measures for the teams. We report four schedules (conference realignments) based on (a) each quality measure (MOV and ELO) and (b) one year's quality measures (2010) or a ten year average quality measure.

For each schedule we ranked the teams from 1 to 118 . The teams are ranked based either on their quality at the beginning of the 2010 season or their average quality at the beginning of 
the season for the previous 10 years (2001-2010). We then put the top 13 teams in the first conference, the next 13 teams in the next conference, and so on. We then gave each team a 12 game schedule, 6 home games and 6 road games with the other 12 teams in the conference. Therefore, each team's entire schedule is with other team's within the conference. Each team's schedule is balanced in the sense that if they play the best team at home, they play the next best team on the road, the next team at home, and so on. This mandates that each team plays one-half of their games at home and one-half of their games away. This balanced scheduling process generates a slightly smaller number of games than are currently played in a season.

Recall that demand in our model is determined by quality, which is in turn determined by performance results. For the simulation we need to update quality throughout the season. We did this by assuming that each team's quality measure is updated throughout the season in the way that the measures actually did change in 2010. For example, for a team's third road game, their quality measure was the same as that team's quality measure when they played their third game in 2010. If a team did not have 6 home games, or 6 road games, their last home/road quality measure was used. ${ }^{10}$ Unfortunately, with 118 teams, there is one team left over after teams have been assigned to 9 conferences. In the simulation, this team plays a generic Football Championship Subdivision team for each game.

The four proposed conferences are shown in Tables 6-9. Tables 6 and 7 are based only on quality as measured in 2010, tables 8 and 9 are based on average quality measured between 2001 and 2010. Tables 6 and 8 are calculated on the basis of the MOV measure, tables 7 and 9 on the basis of the ELO measure.

These schedules are optimal in the sense that the best teams (based on the relevant quality measure) are playing the best teams, which increases demand for college football. However, this does cause a decrease in rivalry games, which is a major complaint about conference realignment. Another factor that can decrease overall attendance is that each team has 6 home games and 6 road games. Currently, teams with high demand typically have more home games than road games, thereby increasing aggregate attendance.

Table 10 shows the results from the various schedules. The first row in Table 10 shows that our stratified schedule does have fewer games, due to the fact that this schedule is balanced. The second row shows the average per game attendance for teams. It is important to note that these numbers are an average of the average attendance for each team. The results show that a completely random schedule is just slightly worse (by between $1 / 3 \%$ and $1 / 2 \%$ on average) than the current conference scheduling. The random schedule by definition does not give priority to rivalry games, suggesting that the rivalry effect is not especially strong. The impacts are relatively small, which gives some evidence that the number of out of conference 
games creates schedules that are not that far different, in terms of strength of schedule, from a completely random schedule. Also it is important to note that while this simulation randomly assigned visiting teams, the home teams were the same as the actual home teams in 2010, and these home teams tended to be the ones with the larger stadiums. If we had randomly assigned home field advantage as well, then the average stadium size would have been smaller and so this random schedule would have had yet lower attendance.

By contrast, the stratified schedule which matches teams of roughly equal strength (and also has fewer rivalry games), increases the average per game attendance between $1 \%$ and $2 \%$. This increase is due to the interaction between home and road team qualities.

The fourth row shows the total attendance for the year. Since there are $3.85 \%$ fewer games in our stratified simulations we multiply the stratified attendance total by 1.0385 . This is equivalent to assuming that each team played 6.23 home games so that there were 729 games total. In our stratified simulation each team plays the same number of home games. Under this scenario, total attendance actually drops roughly $3 \%$. This is because any increase in demand from scheduling more evenly ranked teams is more than offset by the fact that teams that generally have a high attendance are forced to have fewer home games.

For example, the biggest beneficiary of moving to a stratified schedule based on a 10 year average is Navy. Using the MOV metric, their per game attendance would go from 33,952 to 35,456 and the number of home games goes from 5 to 6.23 . Therefore their total attendance would go from 169,759 to 220,921 for a gain of 51,162. Most of this gain is due to the increase in the number of home games instead of the increase in per game attendance. The biggest drop in attendance would happen to Ohio St. While their per game attendance goes from 113,611 to 115,614 , their number of home games would go from 8 to 6.23 . Therefore, their total attendance would go from 908,889 to 720,361 , which is a drop of 188,528 .

If the goal of the NCAA was to continue having balanced conferences, then the conferences would need to be realigned periodically, presumably yearly. We note that changes in conference realignment would be less dramatic if they used quality measures that were averaged over the previous 10 seasons.

\section{Costs of Realignment}

The realignment simulated here would create a hierarchy of divisions containing equally matched teams, and thus resembles the structure of professional soccer leagues in Europe. There teams play in hierarchically organized divisions linked by the promotion and relegation rule. This requires that the worst performing teams, measured by success on the field, are relegated at the end of the season to the immediately inferior division, to be replaced for the 
following season by the best performing teams from that division. Teams can and do move up and down the hierarchy depending on the quality of their play.

Our simulation shows that this realignment would lead to lower attendance, mainly due to the fact that the higher quality teams with larger stadiums would play fewer games at home.

While there is a loss of rivalry games, the main cost is the change in home games for teams with large stadiums. $4.4 \%$ of the games in our sample are considered rivalry games and our largest estimates of the impact of those games is a $12.6 \%$ increase in attendance. Therefore, we estimate rivalry games to account for $.56 \%$ or less of total attendance. Capacity effects from balanced schedules, on the other hand, can decrease aggregate attendance $4 \%$.

However, this effect might only be short term. Given that demand should increase for each team, (because the matching effect generates more attractive games) then all teams might increase capacity in the longer run to meet increased demand. We did not find a strong rivalry game effect, and even if demand was reduced somewhat by the loss of rivalry games, the results imply that it might not be too difficult to generate new rivalry games. In any case, the realignment was intended solely to maximize assortative matching, but it is possible to generate alternative models which improves the balance of matches while preserving more rivalry games. ${ }^{11}$ It also seems plausible that the greatest benefit of increasing balance in competition might not be increased attendance at the stadium but increased media interest.

However, there are other costs involved with realignment. Given that the current conferences are largely based on geography, making conferences more performance based would increase travel costs since teams would be further away. These travel costs are not only of the form of direct financial costs, but might also include a reduced willingness of visiting fans to attend games, which would thereby reduce attendance. ${ }^{12}$ A related point is that this may cause problems with other college sports. Many of the current conferences embrace all sports and hence a realignment based on college football might drastically increase travel costs for Athletic Departments.

There could be adverse effects due to the fact that conferences would change. While our model attempts to control for rivalry games, there may be a positive effect on demand from maintaining conference stability over a long time period. Also, if it turned out that there was little long term mobility up and down the hierarchy then schools that were perpetually at the bottom might lose demand because of the lost opportunity to play occasional games against highly ranked teams.

\section{Conclusions}


In this paper we have simulated an optimal league structure for college football derived from our estimates of team quality (based on results) and the empirical relationship between attendance and the quality of the home and away teams. We find that the restructuring would yield a small increase in attendance. We do not find that the loss of rivalry games due to restructuring would lead to significantly adverse effects on attendance. It is commonplace in sports competition to match contestants of similar ability. In a league format, players of similar ability are usually classed together although there may be some opportunities to move between classes (in knock-out competition organizers usually prefer to seed players so that the best do not meet in the early rounds). Arguably this matching occurs because people like to see the best play against the best.

Sports economics has tended to focus on the competitive balance hypothesis that demand increases when opponents are equally balanced. This entails the proposition that the best playing against the best (as well as the worst playing against the worst) is more attractive than contests among teams of unequal abilities.

In many contexts it has proved hard to demonstrate clear support for the competitive balance hypothesis, perhaps because leagues often tend to be relatively well balanced. It may be that the disparities in some college football games are great enough to reveal the competitive balance effect. Indeed, we know that strong teams often choose to play against very weak opponents, and our analysis shows that this comes at a cost in terms attractiveness to fans, even if our simulations suggest that there are offsetting benefits within the current system.

The competitive balance hypothesis has been used as an argument in favor of redistribution among teams that are already members of a league. In the college football context, where teams have discretion to choose who they play during the season, the implications are rather different. It is not surprising that teams have incentives to pick very weak opponents, all else equal. There are benefits in terms preparing players for stronger opponents ahead, and also in terms of creating an aura of invincibility (even if this is not always entirely credible).

Were the NCAA free to design the entire conference system from scratch, then we suppose they would pick a structure along the lines we have identified. More interestingly, will realignments driven by individual choice lead ultimately to balanced divisional structure of the type we have simulated? There are reasons to think that they will, given that strong teams potentially gain revenues when they commit to playing more games against other strong teams, and there are clear benefits to be seen to be playing at the highest level. We believe that conference realignments are evidence of this process at work. That said this process could take decades or more complete. 
Finally, we draw a parallel between this problem and the issues facing European soccer competition. In Europe teams are traditionally organized in national leagues, but the most attractive competition format is generally thought to be UEFA Champions League, where teams from different countries play each other. The problem with this system is that the top teams in different countries (e.g. Barcelona, Bayern Munich, Manchester United or AC Milan) seldom get to play each other. For many years now there have been discussions about the creation of a European "Superleague" - and although this has not materialized existing competitions have been reformed to enable the top clubs from different countries to play each other more often than in the past. In our view, that is because fans typically want to see the best play against the best.

\section{References}

[1] Becker, Gary S. "A Theory of Marriage: Part I" Journal of Political Economy, 81(4), (1973), 813-847.

[2] Benz, Men-Andri, Leif Brandes, and Egon Franck, "Do Soccer Associations Really Spend on a Good Thing? Empirical Evidence on Heterogeneity in the Consumer Response to Match Uncertainty of Outcome" Contemporary Economic Policy, 27(2), (2009), 216-235.

[3] Borland, Jeff and Robert Macdonald, "The Demand for Sports" Oxford Review Of Economic Policy, 19(4), (2003), 478-502.

[4] Buraimo, Babatunde, David Forrest, and Robert Simmons, "Insights for clubs from modelling match attendance in football" Journal of the Operational Research Society 60 , (2009), 147-155.

[5] Buraimo, Babatunde and Robert Simmons, "Do Sports Fans Really Value Uncertainty of Outcome? Evidence from the English Premier League" International Journal of Sports Finance, 3 (3), (2008), 146-155.

[6] Coates, Dennis and Brad R. Humphreys "Week to week attendance and competitive balance in the National Football League" International Journal of Sport Finance, 5, (2010), 239-252.

[7] Coates, Dennis and Brad R. Humphreys, "Game Attendance and Outcome Uncertainty in the National Hockey League" Journal of Sports Economics 13(4), (2012), 364-377.

[8] Davis, Michael C. "Analyzing the Relationship Between Team Success and MLB Attendance with GARCH Effects" Journal of Sports Economics, 10(1), (2009), 44-58. 
[9] DeSchriver, Timothy D. and Paul E. Jensen, "Determinants of Spectator Attendance at NCAA Division II Football Contests” Journal of Sport Management, 16, (2002), 311-330.

[10] Elo, Arpad E. The rating of chessplayers, past and present. Arco Pub., (1978).

[11] Forrest, D., J. Beaumont, J. Goddard, and R. Simmons, "Home advantage and the debate about competitive balance in professional sports leagues" Journal of Sports Sciences, 23(4), (2005), 439-45.

[12] Forrest, David, and Robert Simmons, "New issues in attendance demand: The case of English League Football” Journal of Sports Economics, 7(3), (2006), 247-266.

[13] Fort, Rodney and Jason Winfree, "15 Sports Myths and Why They're Wrong" Stanford University Press. (2013).

[14] Fréchette, Guillaume R., Alvin E. Roth and M. Utku Ünver "Unraveling yields inefficient matchings: evidence from post-season college football bowls" RAND Journal of Economics, 38(4), (2007), 967-982.

[15] Gale, D. and L. S. Shapley "College Admissions and the Stability of Marriage" American Mathematical Monthly, 69, (1962), 9-15.

[16] Groza, Mark D. "NCAA Conference Realignment and Football Game Day Attendance" Managerial and Decision Economics, 31(8), (2010), 517-529.

[17] Hvattum, L.M. and H. Arntzen, 2010. "Using ELO ratings for match result prediction in association football” International Journal of Forecasting, 26(3), (2010), 460-470.

[18] Humphreys, Brad R. "The Relationship Between Big-Time College Football and State Appropriations for Higher Education" International Journal of Sport Finance, (1), (2006), 119-128.

[19] Keener, James P. "The Perron-Frobenius Theorem and the Ranking of Football Teams" SIAM Review, 35(1), (1993), 80-93.

[20] Kremer, Michael, "The O-Ring Theory of Economic Development", Quarterly Journal of Economics, 108, (1993), 551-575.

[21] Legros, Patrick and Andrew F. Newman "Monotone Matching in Perfect and Imperfect Worlds" Review of Economic Studies, 69(4), (2002), 925-942. 
[22] Lemke, Robert J., Matthew Leonard, and Kelebogile Tlhokwane, "Estimating attendance at major league baseball games for the 2007 season" Journal of Sports Economics, 11(3), (2009), 316-348.

[23] Meehan Jr., James W., Randy A. Nelson and Thomas V. Richardson "Competitive balance and game attendance in major league baseball" Journal of Sports Economics, 8(6), (2007), 563-580.

[24] Mongeon, Kevin and Winfree, Jason, "Comparison of television and gate demand in the National Basketball Association" Sport Mangement Review, 15(1), (2012), 72-79.

[25] Paul, Rodney, Brad R. Humphreys and Andrew Weinbach "Uncertainty of Outcome and Attendance in College Football: Evidence from Four Conferences" The Economic and Labour Relations Review 23(2), (2012), 69-82.

[26] Powell, James L. "Least absolute deviations estimation for the censored regression model" Journal of Econometrics, 25(3), (1984), 303-325.

[27] Pope, Devin G. and Jaren C. Pope, "The impact of college sports success on the quantity and quality of student applications" Southern Economic Journal, 75(3), (2009), 750-780.

[28] Price, Donald I. and Kabir C. Sen, "The demand for game day attendance in college football: An analysis of the 1997 division 1-A season" Managerial and Decision Economics, 24, (2003), 35-46.

[29] Rascher, Daniel A. and John Solmes, "Do fans want close contests? A test of the uncertainty of outcome hypothesis in the National Basketball Association" International Journal of Sport Finance, 2, (2007), 130-141.

[30] Rhoads, Thomas A. and Shelby Gerking, "Educational contributions, academic quality, and athletic success" Contemporary Economic Policy, 18(2), (2000), 248 -258.

[31] Sattinger, Michael, "Assignment Models of the Distribution of Earnings" The Journal of Economic Literature, 31(2), (1993), 831-880.

Table 1 Previous Studies

\begin{tabular}{|l|l|l|l|l|l|}
\hline Paper & sport & Price? & $\begin{array}{l}\text { UOHmeasur } \\
e\end{array}$ & Sign & Significant \\
\hline $\begin{array}{l}\text { DeSchriver \& } \\
\text { Jensen (2002) }\end{array}$ & $\begin{array}{l}\text { College } \\
\text { football }\end{array}$ & Yes (+, sig) & $\begin{array}{l}\text { Homewpcbyse } \\
\text { asonquarter }\end{array}$ & + & $\begin{array}{l}\text { Yes, mostly in } \\
\text { Q4 }\end{array}$ \\
\hline $\begin{array}{l}\text { Price \& Sen } \\
(2003)\end{array}$ & $\begin{array}{l}\text { College } \\
\text { football }\end{array}$ & Yes (-, sig) & Homewpc & + & Yes \\
\hline
\end{tabular}




\begin{tabular}{|c|c|c|c|c|c|}
\hline & & & Awaywpc & + & Yes \\
\hline & & & Diffwpc ${ }^{2}$ & - & No \\
\hline $\begin{array}{l}\text { Paul, } \\
\text { Humphreys \& }\end{array}$ & $\begin{array}{l}\text { College } \\
\text { football }\end{array}$ & No & Homewin\%, & + & Yes \\
\hline \multirow[t]{2}{*}{$\begin{array}{l}\text { Weinbach } \\
(2012)\end{array}$} & & & pointsspread, & + & Yes \\
\hline & & & under/over & + & Yes \\
\hline \multirow[t]{3}{*}{ Groza (2010) } & $\begin{array}{l}\text { College } \\
\text { football }\end{array}$ & No & HomeWpc & + & Yes \\
\hline & & & Sagarinrating & + & Yes \\
\hline & & & Diffsag $^{2}$ & - & Yes \\
\hline \multirow{5}{*}{$\begin{array}{l}\text { Coates \& } \\
\text { Humphreys } \\
(2010) \\
\end{array}$} & NFL & No & Homewpc & + & Yes \\
\hline & & & Awaywpc & + & Yes \\
\hline & & & | Pointsspread & + & Yes \\
\hline & & & $\begin{array}{l}\mid \text { Pointsspread } \\
{ }_{2} \mid\end{array}$ & - & Yes \\
\hline & & & $\begin{array}{l}\mid \text { Pointsspread } \\
* \\
\text { homeunderdo } \\
g \mid\end{array}$ & - & Yes \\
\hline $\begin{array}{l}\text { Meehan } \\
\text { Nelson \& }\end{array}$ & MLB & Yes (+, sig) & Homewpc & + & Yes \\
\hline \multirow[t]{5}{*}{$\begin{array}{l}\text { Richardson } \\
\text { (2007) }\end{array}$} & & & $\begin{array}{l}\text { HomeGBdivlea } \\
\text { der }\end{array}$ & - & Yes \\
\hline & & & $\begin{array}{l}\text { AwayGBdivlea } \\
\text { der }\end{array}$ & - & Yes \\
\hline & & & $\begin{array}{l}\text { Wpcdiffabsolu } \\
\text { te }\end{array}$ & - & Yes \\
\hline & & & Wpcdiff + & - & Yes \\
\hline & & & Wpcdiff - & + & Yes \\
\hline $\begin{array}{l}\text { Lemke, } \\
\text { Leonard \& }\end{array}$ & MLB & Yes (+, sig) & Homewinprob & - & Marg \\
\hline \multirow[t]{2}{*}{$\begin{array}{l}\text { Tlhokwane } \\
\text { (2009) }\end{array}$} & & & $\begin{array}{l}\text { Homewinprob } \\
2\end{array}$ & + & Marg \\
\hline & & & $\begin{array}{l}\text { Playoffchance } \\
s\end{array}$ & various & Marg \\
\hline Davis (2009) & $\mathrm{NL}$ & No & Homewpc $>.5$ & + & yes \\
\hline \multirow[t]{2}{*}{$\begin{array}{l}\text { Coates \& } \\
\text { Humphreys } \\
\text { (2011) }\end{array}$} & $\mathrm{NHL}$ & No & Probhomewin & + & Yes, if $>.584$ \\
\hline & & & Homewpc & - & No \\
\hline
\end{tabular}

This article is protected by copyright. All rights reserved. 


\begin{tabular}{|c|c|c|c|c|c|}
\hline & & & Awaywpc & + & Yes \\
\hline \multirow[t]{8}{*}{$\begin{array}{l}\text { Rascher \& } \\
\text { Solmes (2007) }\end{array}$} & NBA & Yes(-, NS) & (i)Wpchome & + & No \\
\hline & & & Wpchome $e^{2}$ & + & No \\
\hline & & & Wpcaway & + & No \\
\hline & & & Wpcaway $^{2}$ & + & No \\
\hline & & & Diffinwpc & - & No \\
\hline & & & ${\text { Diffin } w p c^{2}}^{2}$ & - & No \\
\hline & & & $\begin{array}{l}\text { (ii)Homewinpr } \\
o b\end{array}$ & + & Yes \\
\hline & & & $\begin{array}{l}\text { Homewinprob } \\
\text { Hom }\end{array}$ & - & Yes \\
\hline \multirow[t]{5}{*}{$\begin{array}{l}\text { Simmons \& } \\
\text { Buraimo } \\
(2008)\end{array}$} & EPL & No & $\begin{array}{l}\text { Homeptsperga } \\
\text { me }\end{array}$ & + & Yes \\
\hline & & & $\begin{array}{l}\text { Awayptsperga } \\
\text { me }\end{array}$ & + & Yes \\
\hline & & & Theilmeasure & - & Yes \\
\hline & & & Probhomewin & - & Yes \\
\hline & & & Probhomewin $^{2}$ & + & Yes \\
\hline \multirow[t]{4}{*}{$\begin{array}{l}\text { Forrest et al. } \\
(2005)\end{array}$} & Eng. Foot. Lea. & No & $\begin{array}{l}\text { Homepointspe } \\
\text { rgame }\end{array}$ & + & Yes \\
\hline & (3 division) & & $\begin{array}{l}\text { Awaypointspe } \\
\text { rgame }\end{array}$ & - & No \\
\hline & & & Probratio & - & Yes \\
\hline & & & Probratio $^{2}$ & + & Yes \\
\hline \multirow{4}{*}{$\begin{array}{l}\text { Forrest \& } \\
\text { Simmons } \\
(2006) \\
\end{array}$} & FLC & No & Homepoints & + & Yes \\
\hline & & & Awaypoints & + & Yes \\
\hline & & & $\begin{array}{l}\text { Hometeamho } \\
\text { meform }\end{array}$ & + & Yes \\
\hline & & & $\begin{array}{l}\text { Points/gamedi } \\
\text { fferenceadjust } \\
\text { ed }\end{array}$ & $?$ & No \\
\hline $\begin{array}{l}\text { Buraimo, } \\
\text { Forrest, }\end{array}$ & FLC & No & $\begin{array}{l}\text { Homeptsperga } \\
\text { me }\end{array}$ & + & Yes \\
\hline $\begin{array}{l}\text { \& Simmons } \\
(2009)\end{array}$ & & & $\begin{array}{l}\text { Awayptsperga } \\
\text { me }\end{array}$ & + & Yes \\
\hline \multirow[t]{3}{*}{$\begin{array}{l}\text { Benz et al } \\
(2009)\end{array}$} & Bundesliga & Yes $(-$, NS) & $\begin{array}{l}\text { Diffinleaguepo } \\
s\end{array}$ & - & No \\
\hline & & & $\begin{array}{l}\text { Diffinptsperga } \\
\text { me }\end{array}$ & - & No \\
\hline & & & Theil & - & No \\
\hline
\end{tabular}

This article is protected by copyright. All rights reserved. 


\begin{tabular}{|l|l|l|l|l|l|}
\hline & & $\begin{array}{l}\text { Relativewinpr } \\
\text { ob }\end{array}$ & - & No \\
\hline & & & Probhomewin $^{2}+$ & No \\
\hline & & & Probhomewin $^{2}$ & + & No \\
\hline & & & & & \\
\hline
\end{tabular}

Table 2 Estimation of Margin of Victory ${ }^{13}$

\begin{tabular}{|l|l|l|}
\hline Variable & Estimate & t-statistic \\
\hline$B_{1}$ & $6.575^{* * *}$ & 4.17 \\
\hline$B_{2}$ & $-3.331^{* * *}$ & -5.59 \\
\hline$B_{3}$ & $48.663^{* * *}$ & 26.86 \\
\hline$B_{4}$ & $39.167^{* * *}$ & 29.85 \\
\hline$B_{5}$ & $26.409^{* * *}$ & 10.64 \\
\hline$B_{6}$ & $71.260^{* * *}$ & 23.86 \\
\hline$B_{7}$ & $-54.304^{* * *}$ & -28.09 \\
\hline$B_{8}$ & $-39.496^{* * *}$ & -29.21 \\
\hline$B_{9}$ & $-29.737^{* * *}$ & -14.31 \\
\hline$B_{10}$ & $-70.739^{* * *}$ & -24.08 \\
\hline$B_{11}$ & $0.345^{* * *}$ & 19.32 \\
\hline$N$ & 14278 & \\
\hline$R^{2}$ & .37 & \\
\hline$\%$ of games predicted correctly & .73 & \\
\hline
\end{tabular}

Table 3 List of Rivalry Games

\begin{tabular}{|l|l|}
\hline Air Force & Army \\
\hline Air Force & Navy \\
\hline Alabama & Auburn \\
\hline Alabama & LSU \\
\hline Arizona & Arizona State \\
\hline Army & Navy \\
\hline California & Stanford \\
\hline Duke & North Carolina \\
\hline Florida & Georgia \\
\hline Florida & Florida State \\
\hline Florida State & Miami \\
\hline Georgia & Georgia Tech \\
\hline Indiana & Purdue \\
\hline lowa & lowa State \\
\hline Kansas & Kansas State \\
\hline Kansas & Missouri \\
\hline
\end{tabular}

This article is protected by copyright. All rights reserved. 


\begin{tabular}{|l|l|}
\hline Michigan & Michigan State \\
\hline Michigan & Notre Dame \\
\hline Michigan & Ohio State \\
\hline Mississippi State & Ole Miss \\
\hline Notre Dame & Stanford \\
\hline Notre Dame & USC \\
\hline Oklahoma & Oklahoma State \\
\hline Oklahoma & Texas \\
\hline Oregon & Oregon State \\
\hline Pittsburgh & West Virginia \\
\hline Texas & Texas A\&M \\
\hline UCLA & USC \\
\hline Utah & Utah State \\
\hline Virginia & Virginia Tech \\
\hline Washington & Washington State \\
\hline
\end{tabular}

Table 4 Summary Statistics for Attendance Estimation

\begin{tabular}{|l|l|l|l|l|}
\hline Variable & Mean & $\begin{array}{l}\text { Standard } \\
\text { Deviation }\end{array}$ & Maximum & Minimum \\
\hline Attendance & 53092 & 26835 & 113090 & 1535 \\
\hline MOVH & 26.822 & 9.227 & 49.088 & 0.068 \\
\hline MOVA & 47.026 & 10.200 & 71.732 & 0 \\
\hline ELOH & 1.092 & 0.229 & 1.620 & 0.452 \\
\hline ELOA & 0.962 & 0.281 & 1.590 & 0.304 \\
\hline Sep & 0.355 & 0.478 & 1 & 0 \\
\hline Oct & 0.315 & 0.465 & 1 & 0 \\
\hline Nov & 0.285 & 0.451 & 1 & 0 \\
\hline Dec & 0.018 & 0.131 & 1 & 0 \\
\hline Rival & 0.044 & 0.206 & 1 & 0 \\
\hline 2001 & 0.051 & 0.219 & 1 & 0 \\
\hline 2002 & 0.063 & 0.243 & 1 & 0 \\
\hline 2003 & 0.059 & 0.236 & 1 & 0 \\
\hline 2004 & 0.061 & 0.240 & 1 & 0 \\
\hline 2005 & 0.070 & 0.255 & 1 & 0 \\
\hline 2006 & 0.095 & 0.294 & 1 & 0 \\
\hline 2007 & 0.111 & 0.315 & 1 & 0 \\
\hline 2008 & 0.143 & 0.350 & 1 & 0 \\
\hline 2009 & 0.151 & 0.358 & 1 & 0 \\
\hline 2010 & 0.151 & 0.358 & 1 & 0 \\
\hline & & & & \\
\hline
\end{tabular}

Table 5 Attendance Estimation (year and stadium fixed effects not shown) ${ }^{1415}$ 


\begin{tabular}{|c|c|c|c|c|c|c|c|c|}
\hline & OLS & $\begin{array}{l}\text { OLS } \\
\text { sub }\end{array}$ & CLAD & Tobit & OLS & $\begin{array}{l}\text { OLS } \\
\text { sub }\end{array}$ & CLAD & Tobit \\
\hline \multirow[t]{2}{*}{$M V_{H}$} & $283^{* * *}$ & $115^{*}$ & $252^{* * *}$ & $191^{* * *}$ & & & & \\
\hline & $(6.64)$ & $(1.91)$ & $(4.01)$ & $(5.56)$ & & & & \\
\hline \multirow[t]{2}{*}{$M_{O} V_{A}$} & $114^{* * *}$ & 33.4 & $73.2^{* *}$ & $60.1^{* *}$ & & & & \\
\hline & $(4.61)$ & $(1.04)$ & $(2.02)$ & $(2.43)$ & & & & \\
\hline \multirow[t]{2}{*}{$\begin{array}{l}\operatorname{MOV}_{H}^{*} \\
\operatorname{MOV}_{A}\end{array}$} & 0.891 & $5.24 * * *$ & 1.84 & $4.1 * * *$ & & & & \\
\hline & $(1.04)$ & $(4.23)$ & $(1.41)$ & $(3.00)$ & & & & \\
\hline \multirow[t]{2}{*}{$E L O_{H}$} & & & & & $\begin{array}{l}21264 * * \\
*\end{array}$ & $\begin{array}{l}16456 * * \\
*\end{array}$ & $\begin{array}{l}18908 * * \\
*\end{array}$ & $\begin{array}{l}19714^{* *} \\
*\end{array}$ \\
\hline & & & & & (13.79) & (7.51) & $(12.05)$ & (7.90) \\
\hline \multirow[t]{2}{*}{$E L O_{A}$} & & & & & $7263 * * *$ & 251 & $4039 * *$ & 2679 \\
\hline & & & & & $(4.78)$ & $(0.12)$ & $(2.20)$ & $(1.23)$ \\
\hline \multirow[t]{2}{*}{$\begin{array}{l}E L O_{H} * \\
E L O_{A} \\
\end{array}$} & & & & & -816 & $7074 * * *$ & 1960 & $4733^{* *}$ \\
\hline & & & & & $(-0.60)$ & $(3.56)$ & (1.18) & $(2.18)$ \\
\hline \multirow[t]{2}{*}{ Sep } & -119 & -1104 & 157 & 264 & -479 & $-1606 * *$ & -337 & -149 \\
\hline & $(-0.24)$ & $(-1.53)$ & $(0.32)$ & $(0.48)$ & $(-1.00)$ & $(-2.27)$ & $(-0.74)$ & $(-0.19)$ \\
\hline \multirow[t]{2}{*}{ Oct } & -265 & $-1781^{* *}$ & 102 & 36.1 & $\begin{array}{l}- \\
1304 * * *\end{array}$ & $\begin{array}{l}- \\
3003 * * *\end{array}$ & $-1151^{* *}$ & -1230 \\
\hline & $(-0.54)$ & $(-2.45)$ & $(0.22)$ & $(0.06)$ & $(-2.68)$ & $(-4.19)$ & $(-2.49)$ & $(-1.40)$ \\
\hline \multirow[t]{2}{*}{ Nov } & $-947^{*}$ & - $3017^{* * *}$ & $-806^{*}$ & -657 & $\begin{array}{l} \\
2328 * * *\end{array}$ & $\begin{array}{l}- \\
4599 * * *\end{array}$ & $2445^{* * *}$ & $2336 * * *$ \\
\hline & $(-1.93)$ & $(-4.15)$ & $(-1.67)$ & $(-1.46)$ & $(-4.77)$ & $(-6.39)$ & $(-5.11)$ & $(-2.85)$ \\
\hline \multirow[t]{2}{*}{ Dec } & 599 & -714 & -449 & 739 & -892 & $-2390 * *$ & -1340 & -1046 \\
\hline & $(0.79)$ & $(-0.65)$ & $(-0.51)$ & $(0.80)$ & $(-1.19)$ & $(-2.22)$ & $(-1.14)$ & $(-0.87)$ \\
\hline \multirow[t]{2}{*}{ Rivals } & $4600 * * *$ & $6707 * * *$ & $6600 * * *$ & $6114 * * *$ & $4345 * * *$ & $6097 * * *$ & $5796 * * *$ & $5689 * * *$ \\
\hline & $(11.71)$ & $(11.23)$ & (6.14) & $(9.58)$ & $(11.20)$ & $(10.38)$ & $(4.77)$ & $(8.53)$ \\
\hline$R^{2}$ & 0.963 & 0.933 & & & 0.964 & 0.935 & & \\
\hline $\begin{array}{l}\text { Log } \\
\text { Likelihoo } \\
\text { d }\end{array}$ & & & & 41197 & & & & 41114 \\
\hline $\mathrm{N}$ & 4839 & 2771 & 4839 & 4839 & 4839 & 2771 & 4839 & 4839 \\
\hline
\end{tabular}

Table 6 Conference alignment from MOV variable for 2010 season $^{16}$

\begin{tabular}{|l|l|l|}
\hline Conference 1 & Conference 2 & Conference 3 \\
\hline Texas & Arizona & Arkansas \\
\hline Alabama & Oregon State & Utah \\
\hline Cincinnati & LSU & UCLA \\
\hline Boise State & BYU & Oklahoma State \\
\hline
\end{tabular}




\begin{tabular}{|c|c|c|}
\hline Florida & Penn State & Bowling Green \\
\hline Pittsburgh & Georgia Tech & Clemson \\
\hline Wisconsin & Navy & Minnesota \\
\hline Ohio State & Nebraska & Central Michigan \\
\hline lowa & North Carolina & Auburn \\
\hline Oregon & Miami & Georgia \\
\hline TCU & Missouri & Florida State \\
\hline Virginia Tech & West Virginia & Kentucky \\
\hline USC & Oklahoma & SMU \\
\hline Conference 4 & Conference 5 & Conference 6 \\
\hline Washington & Syracuse & Middle Tennessee \\
\hline Troy & Rutgers & Idaho \\
\hline Mississippi State & Stanford & Northern Illinois \\
\hline Marshall & Boston College & Louisiana Lafayette \\
\hline Texas Tech & Fresno State & Utah State \\
\hline South Carolina & South Florida & Ohio \\
\hline Tennessee & UCF & lowa State \\
\hline East Carolina & Nevada & Louisiana Monroe \\
\hline Purdue & Notre Dame & Texas A\&M \\
\hline Air Force & California & Temple \\
\hline Ole Miss & Southern Miss & Florida Atlantic \\
\hline Northwestern & Michigan State & Louisville \\
\hline Houston & Wyoming & Baylor \\
\hline Conference 7 & Conference 8 & Conference 9 \\
\hline Kansas & San Jose State & Western Michigan \\
\hline Tulsa & NC State & Toledo \\
\hline UNLV & Memphis & Duke \\
\hline Kansas State & Arizona State & North Texas \\
\hline Wake Forest & Louisiana Tech & Tulane \\
\hline Colorado State & Washington State & Vanderbilt \\
\hline Miami $(\mathrm{OH})$ & Illinois & UTEP \\
\hline UAB & Virginia & Rice \\
\hline Hawaii & Army & Kent State \\
\hline Michigan & Indiana & Maryland \\
\hline Buffalo & San Diego State & New Mexico State \\
\hline Colorado & Florida International & Western Kentucky \\
\hline Arkansas State & New Mexico & Ball State \\
\hline
\end{tabular}

Table 7 Conference alignment from ELO variable for 2010 season $^{17}$

\begin{tabular}{|l|l|l|}
\hline Conference 1 & Conference 2 & Conference 3 \\
\hline Florida & TCU & Boston College \\
\hline Texas & Georgia Tech & Clemson \\
\hline
\end{tabular}




\begin{tabular}{|c|c|c|}
\hline Alabama & Utah & Auburn \\
\hline Ohio State & BYU & Pittsburgh \\
\hline USC & Texas Tech & Miami \\
\hline Oregon & lowa & Arkansas \\
\hline Penn State & Oregon State & Arizona \\
\hline Boise State & Nebraska & Missouri \\
\hline Virginia Tech & West Virginia & Ole Miss \\
\hline Oklahoma & Wisconsin & Tennessee \\
\hline Georgia & Florida State & Stanford \\
\hline Cincinnati & California & South Carolina \\
\hline$\angle S U$ & Oklahoma State & Rutgers \\
\hline Conference 4 & Conference 5 & Conference 6 \\
\hline North Carolina & NC State & Maryland \\
\hline Michigan State & Mississippi State & Troy \\
\hline Northwestern & Air Force & Washington \\
\hline Kentucky & Texas A\&M & Hawaii \\
\hline UCLA & Michigan & Colorado \\
\hline South Florida & Purdue & UCF \\
\hline Kansas & Kansas State & Illinois \\
\hline Wake Forest & Houston & lowa State \\
\hline Notre Dame & Fresno State & Middle Tennessee \\
\hline Navy & Virginia & Wyoming \\
\hline East Carolina & Nevada & Southern Miss \\
\hline Central Michigan & Minnesota & Baylor \\
\hline Arizona State & Louisville & Tulsa \\
\hline Conference 7 & Conference 8 & Conference 9 \\
\hline Vanderbilt & Rice & UTEP \\
\hline Indiana & SMU & San Jose State \\
\hline Syracuse & Northern Illinois & Arkansas State \\
\hline Bowling Green & Colorado State & Utah State \\
\hline Washington State & UAB & Memphis \\
\hline Temple & Idaho & Kent State \\
\hline UNLV & Louisiana Lafayette & Army \\
\hline Ohio & New Mexico & Florida International \\
\hline Marshall & Louisiana Monroe & Tulane \\
\hline Duke & Buffalo & New Mexico State \\
\hline Louisiana Tech & Ball State & Miami $(\mathrm{OH})$ \\
\hline Florida Atlantic & San Diego State & Eastern Michigan \\
\hline Western Michigan & Toledo & North Texas \\
\hline
\end{tabular}

Table 8 Conference alignment from average MOV variable from 2001 to 2010 season $^{18}$ Conference 1 Conference 2 Conference 3 


\begin{tabular}{|c|c|c|}
\hline USC & Tennessee & lowa \\
\hline Oklahoma & Auburn & Louisville \\
\hline Texas & Oregon State & UCLA \\
\hline Florida & West Virginia & Oklahoma State \\
\hline LSU & Michigan & South Carolina \\
\hline Ohio State & Alabama & Arkansas \\
\hline Miami & Boston College & Cincinnati \\
\hline Florida State & Wisconsin & Clemson \\
\hline Georgia & Texas Tech & Penn State \\
\hline Virginia Tech & Notre Dame & Maryland \\
\hline Boise State & Georgia Tech & Pittsburgh \\
\hline Oregon & Nebraska & California \\
\hline TCU & Utah & BYU \\
\hline Conference 4 & Conference 5 & Conference 6 \\
\hline Fresno State & Bowling Green & Arizona \\
\hline Texas A\&M & Washington & Northern Illinois \\
\hline Colorado & South Florida & NC State \\
\hline Virginia & Colorado State & Kentucky \\
\hline Southern Miss & Michigan State & Air Force \\
\hline Purdue & Arizona State & Troy \\
\hline Kansas State & North Carolina & Illinois \\
\hline Minnesota & Syracuse & New Mexico \\
\hline Wake Forest & Stanford & Kansas \\
\hline Northwestern & Toledo & Nevada \\
\hline Missouri & Marshall & Miami $(\mathrm{OH})$ \\
\hline Ole Miss & Hawaii & Houston \\
\hline Washington State & East Carolina & Western Michigan \\
\hline Conference 7 & Conference 8 & Conference 9 \\
\hline Rutgers & Ball State & Tulane \\
\hline Tulsa & North Texas & Arkansas State \\
\hline UCF & UTEP & Western Kentucky \\
\hline Mississippi State & UNLV & SMU \\
\hline lowa State & Rice & Louisiana Lafayette \\
\hline Central Michigan & Utah State & New Mexico State \\
\hline Middle Tennessee & San Jose State & Idaho \\
\hline Baylor & Vanderbilt & Kent State \\
\hline Louisiana Tech & Indiana & Louisiana Monroe \\
\hline UAB & Ohio & Duke \\
\hline Memphis & San Diego State & Buffalo \\
\hline Navy & Wyoming & Army \\
\hline Florida Atlantic & Temple & Florida International \\
\hline
\end{tabular}

Table 9 Conference alignment from ELO variable from 2001 to 2010 season $^{19}$ 


\begin{tabular}{|c|c|c|}
\hline Conference 1 & Conference 2 & Conference 3 \\
\hline Texas & Oregon & lowa \\
\hline Florida & Nebraska & Arkansas \\
\hline USC & Wisconsin & Kansas State \\
\hline Oklahoma & Penn State & UCLA \\
\hline Ohio State & Oregon State & Utah \\
\hline Georgia & Boston College & Virginia \\
\hline LSU & Texas Tech & California \\
\hline Miami & Alabama & Maryland \\
\hline Florida State & Georgia Tech & TCU \\
\hline Virginia Tech & Boise State & Purdue \\
\hline Tennessee & Clemson & Louisville \\
\hline Michigan & West Virginia & Texas A\&M \\
\hline Auburn & Notre Dame & Arizona State \\
\hline Conference 4 & Conference 5 & Conference 6 \\
\hline South Carolina & Arizona & Colorado State \\
\hline Colorado & Minnesota & Marshall \\
\hline BYU & Cincinnati & Mississippi State \\
\hline NC State & North Carolina & Air Force \\
\hline Michigan State & South Florida & Illinois \\
\hline Pittsburgh & Fresno State & Toledo \\
\hline Missouri & Northwestern & New Mexico \\
\hline Washington State & Southern Miss & East Carolina \\
\hline Oklahoma State & Kansas & Troy \\
\hline Ole Miss & Hawaii & Bowling Green \\
\hline Washington & lowa State & Indiana \\
\hline Stanford & Kentucky & Miami $(\mathrm{OH})$ \\
\hline Wake Forest & Syracuse & Houston \\
\hline Conference 7 & Conference 8 & Conference 9 \\
\hline Rutgers & Baylor & Duke \\
\hline Northern Illinois & Tulsa & SMU \\
\hline Navy & UNLV & North Texas \\
\hline UCF & Middle Tennessee & Utah State \\
\hline Nevada & Rice & Florida International \\
\hline Louisiana Tech & Tulane & Louisiana Lafayette \\
\hline Memphis & Central Michigan & Arkansas State \\
\hline Vanderbilt & San Jose State & New Mexico State \\
\hline San Diego State & Ball State & Louisiana Monroe \\
\hline Florida Atlantic & Ohio & Kent State \\
\hline Wyoming & UTEP & Idaho \\
\hline UAB & Western Kentucky & Army \\
\hline Western Michigan & Temple & Eastern Michigan \\
\hline
\end{tabular}

This article is protected by copyright. All rights reserved. 
Table 10 Unrestricted Attendance Estimation From Simulation Results ${ }^{20}$

\begin{tabular}{|c|c|c|c|c|c|c|c|c|}
\hline \multicolumn{9}{|l|}{$\begin{array}{l}\text { Schedul } \\
\mathrm{e}\end{array}$} \\
\hline $\begin{array}{l}\text { Estimati } \\
\text { on }\end{array}$ & acutal & & random & & stratified & & $\begin{array}{c}10 \text { year } \\
\text { avg. }\end{array}$ & \\
\hline & MOV & ELO & MOV & ELO & MOV & ELO & MOV & ELO \\
\hline $\begin{array}{l}\text { \# of } \\
\text { games }^{20}\end{array}$ & 729 & 729 & 729 & 729 & 708 & 708 & 708 & 708 \\
\hline \multicolumn{9}{|l|}{ average } \\
\hline \multicolumn{9}{|l|}{$\begin{array}{l}\text { per } \\
\text { game }\end{array}$} \\
\hline $\begin{array}{l}\text { attenda } \\
\text { nce }\end{array}$ & 44,850 & 44,919 & 44,639 & 44,749 & 45,359 & 45,694 & 45,319 & 45,638 \\
\hline \multicolumn{9}{|l|}{$\%$ from } \\
\hline actual & & & $-.47 \%$ & $-.38 \%$ & $1.14 \%$ & $1.72 \%$ & $1.05 \%$ & $1.60 \%$ \\
\hline \multicolumn{9}{|l|}{ total } \\
\hline $\begin{array}{l}\text { attenda } \\
\text { nce }\end{array}$ & $\begin{array}{c}34,103,8 \\
71\end{array}$ & $\begin{array}{c}34,155,6 \\
70\end{array}$ & $\begin{array}{c}33,921,0 \\
20\end{array}$ & $\begin{array}{c}33,986,6 \\
60\end{array}$ & $\begin{array}{c}33,066,6 \\
22\end{array}$ & $\begin{array}{c}33,311,0 \\
03\end{array}$ & $\begin{array}{c}33,037,3 \\
68\end{array}$ & $\begin{array}{c}33,270,3 \\
17\end{array}$ \\
\hline \multicolumn{9}{|l|}{ \% from } \\
\hline actual & & & $-.54 \%$ & $-.49 \%$ & $-3.04 \%$ & $-2.47 \%$ & $-3.13 \%$ & $-2.59 \%$ \\
\hline
\end{tabular}

1

http://en.wikipedia.org/wiki/List_of_schools_changing_conference_in_the_2010\%E2\%80\%9313_NCAA_confer ence_realignmentuploaded 6/6/2013

${ }^{2}$ For example, consider scheduling games one weekend for Michigan (capacity 108,000), Ohio State $(105,000)$, Eastern Michigan $(30,000)$ and Bowling Green $(24,000)$. Assume that team quality is correlated with stadium capacity. Then with positive assortative matching Ohio State plays at Michigan and Bowling Green plays at Eastern Michigan, and if the games are sold out then the total number of tickets sold is 138,000 . Now suppose Eastern Michigan plays at Michigan and Bowling Green at Ohio State, and that due to the lack of positive assortative matching demand is only $75 \%$ of capacity. The total number of tickets sold will now be 160,000 .

${ }^{3}$ Mongeon and Winfree (2012) find that in the National Basketball Association, television audiences are 4.5 times more sensitive to winning than live audiences.

${ }^{4}$ Fort and Winfree $(2013, \mathrm{p} 33)$ point out that research has found a positive correlation between college athletic success and alumni giving (Rhoads and Gerking (2000)), student applications (e.g. Pope and Pope (2009)) and budget allocations by legislators (Humphreys (2006)).

${ }^{5}$ SOS is equal to the average winning percentage of the opponents that the team has played up until that game.

${ }^{6}$ See Elo (1978) for an explanation of the ranking method. Elo ratings have been used for ranking in a number of different sports. See e.g. Hvattum and Artnzen (2010) for an application to soccer.

${ }^{7}$ This does not include Notre Dame because all of their games were censored due to sell outs according to our criteria, explained later in the paper.

${ }^{8}$ If less than $10 \%$ of games were greater than $98 \%$ of the maximum, the censoring issue was not deemed to be severe at that stadium and there is a greater probability that the games are uncensored and randomly within $2 \%$ of the maximum. 
${ }^{9}$ With both OLS estimations, we do not account for censoring and assume $y_{i}=y_{i}^{*}$.

${ }^{10}$ While it might seem arbitrary to assume that quality would evolve in our league structure in the same way that it did in the actual competition structure in 2010 , it seems reasonable to suggest, at least as an approximation, that the quality of a team is independent of the opposing teams. In other words, if the schedule had been different the game scores would have been different, but these should have implied the same quality estimates.

${ }^{11}$ In recent years, there has been some movement of teams across various conferences. Perhaps conferences recognize the value of admitting teams of similar quality, but at the same time maintain rivalry games and allow the larger teams to schedule more home.

12 In Europe the soccer leagues operate within national boundaries and so travel costs do not tend to be important.

$13 * * *$ denotes significance at the $1 \%$ level.

14 "OLS sub" refers to OLS estimates using only teams that have no censored observations

${ }^{15}$ Standard errors for the CLAD estimation was calculted using a bootstrap with 200 replications.

${ }^{16}$ Teams in italics maintained a rivaly game with this conference alignment. Stanford maintained 2 rivalry games. Eastern Michigan was the last ranked team and played Football Championship Subdivision teams in the simulation.

${ }^{17}$ Teams in italics maintained a rivaly game with this conference alignment. Western Kentucky was the last ranked team and played Football Championship Subdivision teams in the simulation.

${ }^{18}$ Teams in italics maintained a rivaly game with this conference alignment. Florida and Florida St. maintained 2 rivalry games. Eastern Michigan was the last ranked team and played Football Championship Subdivision teams in the simulation.

${ }^{19}$ Teams in italics maintained a rivaly game with this conference alignment. Florida and Florida St. maintained 2 rivalry games. Buffalo was the last ranked team and played Football Championship Subdivision teams in the simulation.

${ }^{20}$ Due to the unbalanced schedule, there were a total of 729 home games in the sample. The random simulation only changed opponents and not the dates of home games, therefore there are also 729 home games. The stratified and 10 year average simulations use six home games for each team and therefore there are 702 games in total. However, to find the season's total attendance, each teams average attendance was multiplied by 6.23 to make the comparisons more meaningful. 